\title{
FRACTURE ENERGY OF CERAMICS MEASURED AT DIFFERENT LOADING RATES IN INSTRUMENTED IMPACT TESTS
}

\author{
J.F. KALTHOFF* , U. WALDHERR* * and S. TAKAHASHI*, (1) \\ "Experimentelle Mechanik, Ruhr-Universität Bochum, Bochum, \\ Germany \\ **Werkstoffprüfung, Ruhr-Universität Bochum, Bochum, Germany
}

résumé: L'énergie d'impact d'une céramique est mesurée au cours d'essais de choc sur un nouveau dispositif à grande sensibilité. L'énergie mesurée a une forte tendance à crô̂tre avec la vitesse d'impact. Des observations avec une caméra rapide montrent qu'une proportion considérable de l'énergie d'impact mesurée est convertie en énergie cinétique des moitiés de cible après impact. En déduitsant cette énergie cinétique des valeurs mesurées de l'énergie d'impact, on obtient l'énérgie réelle de rupture, qui ne dépend pas de la vitesse d'impact.

\begin{abstract}
The impact energy of a ceramic material is measured in instrumented impact tests by means of a novel high sensitivity striker tup. The measured impact energy shows a strongly increasing trend with increasing impact velocity. High speed cinematographic investigations indicate that a considerable part of the measured impact energy is transferred into kinetic energy of the moving specimen halves after impact. If this kinetic energy is subtracted from the measured values of the impact energy a quantity representing the true fracture energy is obtained which does not depend on the impact velocity.
\end{abstract}

\section{Introduction}

Increasing efforts are made with modern constructions to replace conventional structural materials such as steels, aluminium alloys etc. by new materials, among them also ceramics. Ceramics, on the one hand side, show a high mechanical strength and a high resistance against ware; on the other hand, they are characterized by a low toughness and thus by a high sensitivity against failure by brittle fracture; properties which render the application of ceramics difficult. Therefore, exact knowledge of the material properties against failure, in particular also under the conditions of impact loading, is an important prerequisite for the reliable use of this material in structures.

This paper reports on the determination of the impact energy or Charpy energy of ceramis at different loading rates measured in instrumented impact tests by a novel measuring technique. The data are discussed with respect to their relevance as reliable material strength characteristics. 

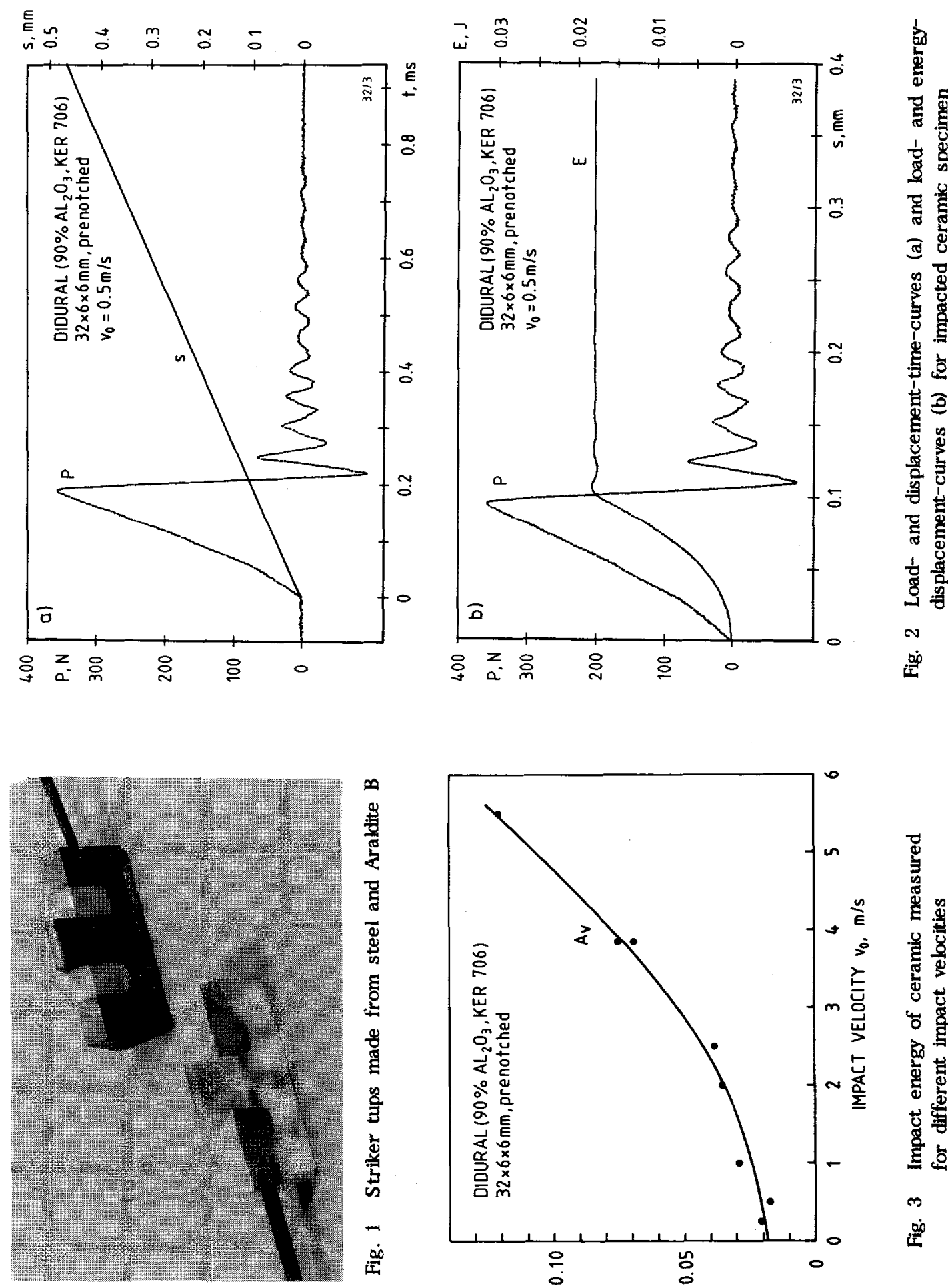

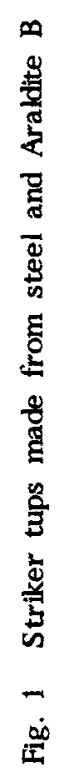

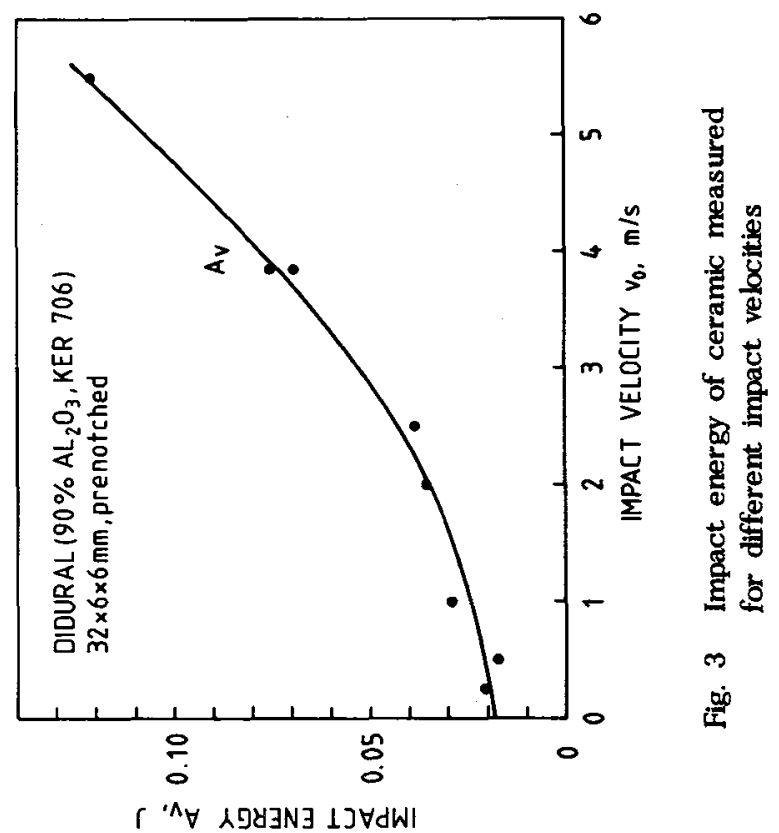




\section{Measuring Technique}

Conventional Charpy pendulum devices for testing steel specimens, but also pendulums of smaller dimensions for testing polymeric specimens, use a striker tup which is usually made from steel. The instrumentation of such tups by strain gauges for measuring load signals during the impact process, however, cannot be used for testing of ceramic specimens: The obtained load values of the order of several $100 \mathrm{~N}$ only result in deformations too small to be measurable with sufficient accuracy. The author, therefore, introduced a striker tup made from a material having a Young's modulus much lower than that of steels $/ 1 /$, consequently, small loads generate sufficiently large deformations that can easily be measured. The epoxy resin Araldite $B$ is used as tup material. This material often serves as model material for photoelastic investigations, it is characterized by a very small variation of its mechanical properties with respect to loading rate, furthermore, by a very high relative strength value. Figure 1 shows an Araldite $B$ tup in comparison to a conventional steel tup for a $300 \mathrm{~J}$ pendulum test device. According to the ratio of Young's moduli $\left(E_{\text {Steel }}=210 \mathrm{GPa}, \mathrm{E}_{\text {Araldite }}=3.66 \mathrm{GPa}\right.$ ) the sensitivity of the Araldite $\mathrm{B}$ tup is by almost two orders of magnitude larger than that of the corresponding steel tup. Following the conventional evaluation procedure for instrumented impact tests, first, the displacement of the specimen is calculated from the measured load-time-record via integration of Newton's law

$$
s(t)=\int\left[v_{0}-\frac{1}{M} \int P(t) d t\right] d t,
$$

secondly, the energy absorbed by the specimen during the impact process is calculated as

$$
E(s)=\int P(s) d s,
$$

where $\quad \begin{aligned} & \mathbf{P}=\text { measured load } \\ & \mathbf{t}=\text { time } \\ & \mathbf{M}=\text { mass of hammer }\end{aligned}$

$$
\begin{aligned}
v_{0}= & (\text { initial }) \text { impact velocity } \\
s= & \text { position of striker tup } \\
& (\hat{=} \text { specimen displacement }) \\
E=\text { energy } &
\end{aligned}
$$

The total energy obtained by integration over the entire impact process represents the impact or Charpy energy $A_{v}$.

The determination of the impact energy via instrumentation of the striker tup and not, as usual, via the difference of the pendulum heights before and after impact has the advantage in that very small impact energies can be measured even with pendulum devices of very large energy contents. The accuracy of the measurement is only determined by the accuracy of the load measurement. The applicability of the high sensitivity striker tup for measuring small loads or small impact energies with polymeric or ceramic specimens in conventional pendulum tests devices has been reported at the 13th GESA-Symposium Experimental Mechanics /1/.

\section{Impact Energy of Ceramics}

With the loading technique described above impact energies are measured for a ceramic at different impact velocities. The experiments have been performed with a $300 \mathrm{~J}$ Wolpert pendulum test device PW 30 modified by an Araldite B striker tup. Data acquisition occurs via the electronic measuring chain Wolpert Prolog 8001 for the registration of load-timerecords. The software Wolpert/Probat Progres $Q$ is used for the determination of displacement-time- and energy-displacement-data. This measuring technique is conventionally utilized for testing steel specimens, in those cases, however, in combination with a striker tup made from steel. The investigations have been performed with a ceramic of the Didier 

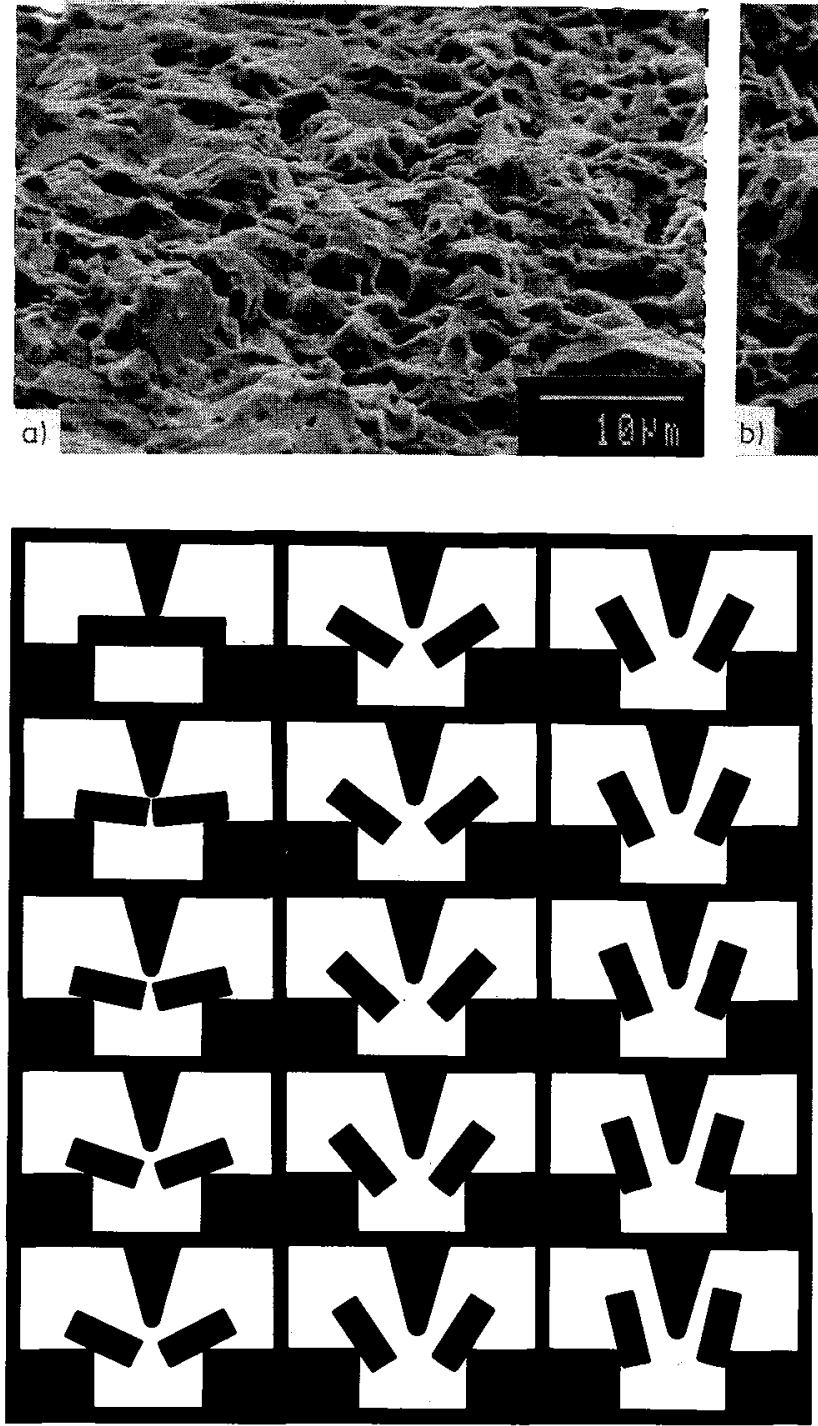

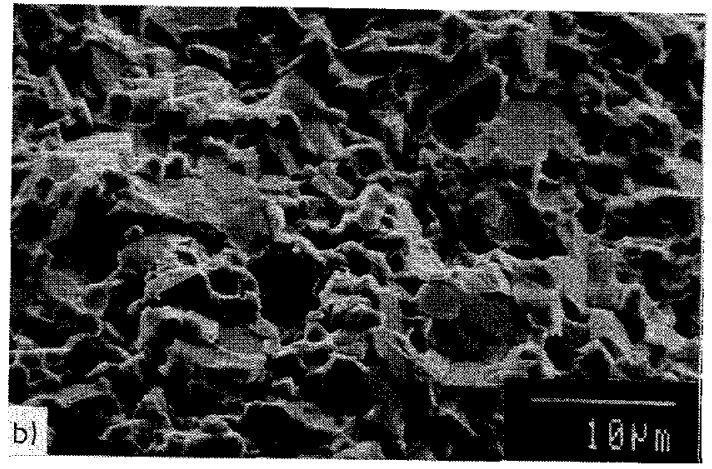

Fig. 4

Micrographs of fracture surfaces obtained at (a) $0.25 \mathrm{~m} / \mathrm{s}$ and (b) $3.85 \mathrm{~m} / \mathrm{s}$ impact velocity
Fig. 5

High speed photographs of the movement of the specimen halves after impact (impact velocity $0.5 \mathrm{~m} / \mathrm{s}$, picture interval time $0.64 \mathrm{~ms}$ )
Fig. o

Positions of moving specimen halves after impact at subsequent time steps (time interval $0.64 \mathrm{~ms}$ )

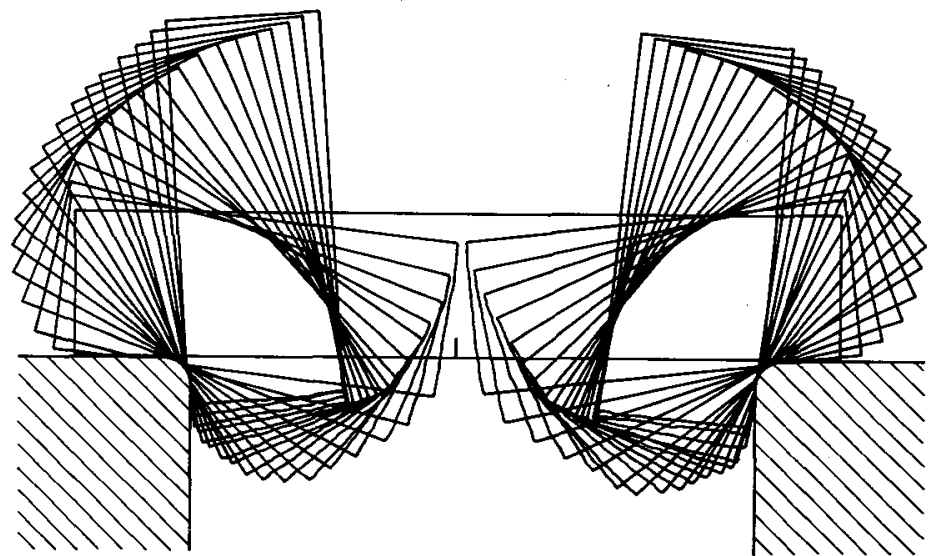


Company, DIDURAL A $90\left(90 \% \quad \mathrm{AL}_{2} \mathrm{O}_{3}, \mathrm{KER}\right.$ 706). The density of this ceramic is $p=3.6 \mathrm{~g} / \mathrm{cm}^{3}$, Young's modulus is $E=230 \mathrm{GPa}$. The measurements of the specimens are $32 \times 6 \times 6 \mathrm{~mm}$; the specimens have been prenotched by a saw cut of $0.8 \mathrm{~mm}$ depth. The support span was $24 \mathrm{~mm}$. The impact velocity has been varied in the range of $0.25 \mathrm{~m} / \mathrm{s}$ to $5.5 \mathrm{~m} / \mathrm{s}$.

A typical set of data of load-time- and displacement-time-curves, as well as load-displacement- and energy-displacement-curves is shown in Fig. 2 for an impact experiment of $0.5 \mathrm{~m} / \mathrm{s}$. Because of the small amount of energy absorbed by the specimen during the impact process compared to the large energy content of the pendulum, the slope of the displacement-time-curve practically does not decrease during the impact event, thus indicating, that the impacting hammer breaks the specimen practically without any noticeable deceleration.

Impact energies $A_{y}$ obtained for different impact velocities $v_{0}$ are presented in Fig. 3 . With increasing impact velocity the impact energy also increases. This result is contradictory to the behaviour observed with other materials, e.g. steels, typically showing a decreasing trend with increasing loading rate; furthermore, it is found that the increase in impact energy by a factor of 6 is very pronounced.

In order to check whether the change in impact energy is associated with a change in the fracture mechanism of the ceramic fractographic investigations have been performed by electron microscopy (Au-sputtered. SE-mode). Areas of the fracture surface directly behind the initial notch were analyzed. Figure 4 shows photographs of the fracture surfaces obtained from experiments with low $(0.25 \mathrm{~m} / \mathrm{s})$ and high $(3.85 \mathrm{~m} / \mathrm{s})$ impact velocities. Significant differences cannot be seen. Transgranular and interfacial fracture about equal in parts are observed in both cases. It must be concluded, therefore, that the increase in impact energy with increasing impact velocity is not attributed to any changes in the fracture mechanism.

Because of the observed unusual findings it seemed necessary to specially investigate whether indeed all the impact energy $A_{y}$ absorbed by the specimen is actually used as fracture energy, or, whether eventually parts of this energy are transferred into kinetic energy of the moving specimen halves after breaking of the specimen.

\section{Influence of Kinetic Energy}

Therefore, the experiments performed with the pendulum test device have been repeated under basically the same experimental conditions but with a drop weight tower. In these experiments the movement of the specimen halves after the impact process has been photographed with a Cranz-Schardin 24 spark high speed camera. The camera was utilized in a special arrangement by which shadow images of the object, i.e. the striking tup, the specimen, and the anvils are recorded. Figure 5 shows 15 of 24 photographs total obtained for an impact experiment of $0.5 \mathrm{~m} / \mathrm{s}$. The picture interval time is $0.64 \mathrm{~ms}$. The graphical representation in Fig. 6 shows the subsequent positions of the moving specimen halves relative to each other in one picture.

For each time step the local coordinates of the specimen halves have quantitatively been determined, and from these data the translational and the rotational velocities of the specimen halves, $v_{T}$ and $\omega_{R}$, were calculated. Quantitative results for an impact experiment with $v_{0}=5 \mathrm{~m} / \mathrm{s}$ are shown for one of the specimen halves in Fig. 7 as a function of time. The large scatter of the data is not astonishing, first, because experimental data are differentiated, and secondly, because the pictures taken with the Cranz-Schardin camera are obtained at observation angles slightly tilted with respect to each other: thus, 
Fig. 7

Translational and rotational velocity of specimen halves after impact
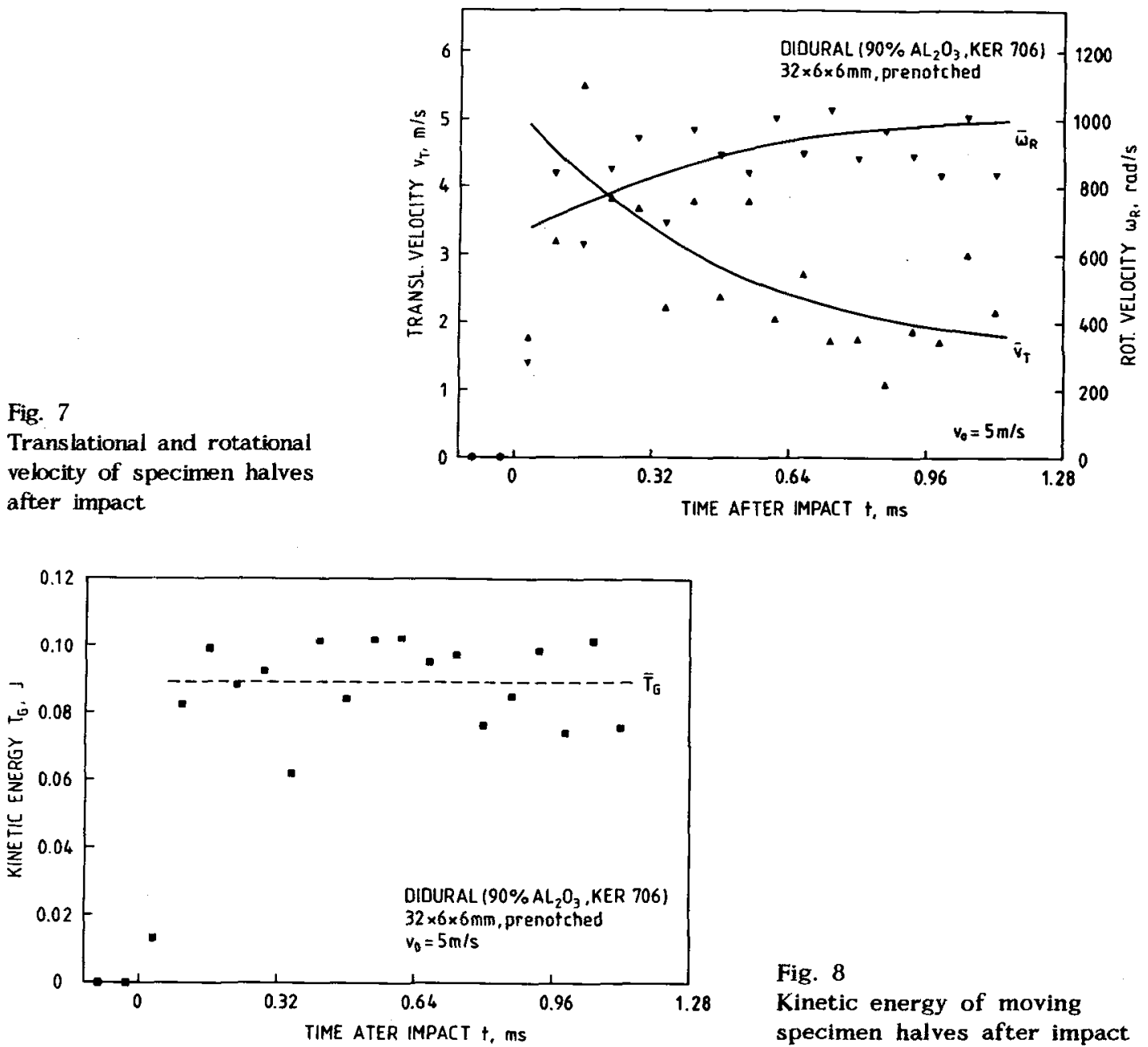

Fig. 8

Kinetic energy of moving specimen halves after impact
Fig. 9

Comparison of kinetic energy of moving specimen halves with measured impact energy

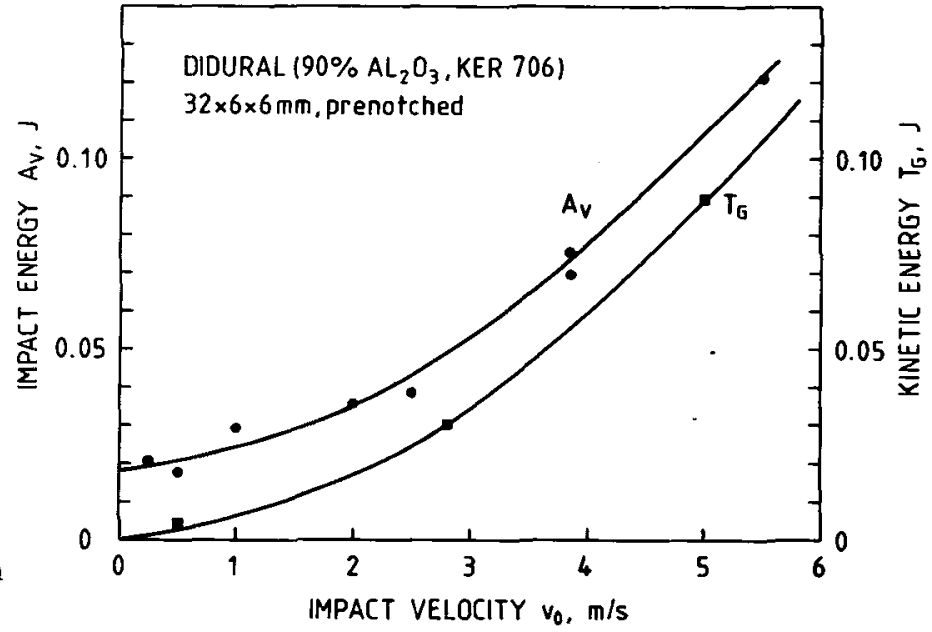


the shadow contour of the specimen halves can either represent the front or the rear edge of the specimen halves appearing at slightly different positions. With an accuracy sufficient for these investigations, however, the mean values of the translational velocity $\bar{v}_{T}$ and of the rotational velocity $\bar{\omega}_{R}$ can be determined. For both specimen halves the velocities are practically the same. The translational velocity $\bar{v}_{T}$ decreases with increasing time, the rotational velocity $\bar{\omega}_{R}$, however, shows an increasing trend with time. Obviously this is an indication that the free movement of the specimen halves is hindered by the edges of the anvils. From the measured velocities the kinetic energy for translation, $T_{T}=\frac{1}{2} m v^{2}$, and for rotation, $T_{R}=\frac{1}{2} \Theta \omega^{2}$, and consequently also the total kinetic energy, $T_{G}=2\left(T_{T}+T_{R}\right)$, can be determined for each time step. The result is shown in Fig. 8 as a function of time. Within the range of experimental scatter a horizontal line is obtained, indicating that obviously the increase in the rotational velocity $\omega_{R}$ on the expense of the reduction of the translational velocity $\mathrm{v}_{\mathrm{T}}$ occurs without any change in the total energy. For three different impact velocities $v_{0}=0.5 / 2.8 / 5.0 \mathrm{~m} / \mathrm{s}$ total kinetic energies $\mathrm{T}_{\mathrm{G}}=0.0042 / 0.0295 / 0.0891 \mathrm{~J}$ have been obtained

\section{Discussion of Results}

The obtained data for the total kinetic energy $T_{G}$ together with the measured data for the impact energy $A_{v}$ are shown in Fig. 9 as a function of the impact velocity $v_{0}$. It is recognized that with brittle materials, as the ceramic investigated, a considerable part of the impact energy - at high impact velocities even the major part - is not transferred into fracture energy of the material, but into kinetic energy of the moving specimen halves. Furthermore, Fig. 9 shows that the curve for the kinetic energy $T_{G}$ is basically parallel to the curve for the impact energy $A_{v}$. With the assumption, that only the difference of the two energy quantities, $A_{v}-T_{G}$, actually represents the energy for breaking the specimen it is concluded that within the range of impact velocities investigated, i.e. 0.25 to $5.5 \mathrm{~m} / \mathrm{s}$, the fracture energy does not depend on loading rate but stays constant, a result which is plausible for brittle materials.

In addition to these investigations experiments have been performed with standard Charpy$\mathrm{V}$-notch specimens made from steel which were tested at low temperatures in the lower shelf regime. The data indicate that the kinetic energy of the specimen halves amounts to about $2 \mathrm{~J}$, i.e., also in this case, to a value representing a considerable part of the lower shelf energy. With steels, however, it is not the lower shelf energy itself, but the transition temperature and the upper shelf energy which is used for characterization of the material; thus, this result is of lesser practical importance. If, however, the determination of fracture properties of brittle materials are of primary concern, the kinetic energy of the specimen halves after impact must be considered in the measurement of the impact energy in order to avoid misinterpretation of the recorded data and to obtain meaningful reliable results.

\section{Literature}

/1/ Kalthoff, J.F., Achterfeldt, K., "Hochsensitive Schlagfinne zur Prüfung von Kunststoffoder Keramikproben im instrumentierten Kerbschlagbiegeversuch", Proceedings 13th GESA-Symposium Experimentelle Mechanik in Forschung und Praxis, Bremen, 10./11. Mai 1990, VDI-Berichte Nr. 815, Diisseldorf, Germany, 1990, 389-402.

/2/ DVM-Merkblatt 001, "Meßtechnische Anforderungen beim instrumentierten Kerbschlagbiegeversuch", Deutscher Verband für Materialprüfung, Berlin, Germany, 1986. 